\title{
Discovery of Next-Generation Tropomyosin Receptor Kinase (TRK) Inhibitors for Combatting Resistance Associated with Protein Mutation
}

\section{Linsheng Zhuo}

central China normal university

\section{Ming-Shu Wang}

Central China Normal University

\section{Feng-Xu Wu}

Hubei University of Medicine

\section{Hong-Chuang Xu}

Central China Normal University

Yi Gong

Central China Normal University

\section{Zhi-Cheng Yu}

Central China Normal University

Yan-Guang Tian

Central China Normal University

Chao Pang

Central China Normal University

Geifei Hao

Guizhou University

Wei Huang

Central China Normal University

Guang-Fu Yang ( $\nabla$ gfyang@mail.ccnu.edu.cn )

Central China Normal University

\section{Article}

Keywords: tropomyosin receptor kinases (TRKs), anticancer therapeutics, TRK inhibitors, drug development

Posted Date: June 17th, 2021

DOI: https://doi.org/10.21203/rs.3.rs-597552/v1 
License: (c) (i) This work is licensed under a Creative Commons Attribution 4.0 International License. Read Full License 


\section{Abstract}

Aberrant signaling from tropomyosin receptor kinases (TRKs) has been identified as the oncogenic driver in a large variety of cancers, suggesting that inhibition of TRK may be an attractive strategy of attack for anticancer therapeutics. Despite the encouraging therapeutic response to the first-generation TRK inhibitor Larotrectinib (1), the emergence of drug-resistant secondary mutations within its ATP-binding pocket cause relapse in cancer patients. A next-generation inhibitor that overcomes multiple Larotrectinibresistant mutations is still a major "unmet clinical need". In this study, the progressive exploration of the structure-activity relationship (SAR) through scaffold hopping, flexibilization, and fluoroalkoxy substitutions produced modifications on the reported compound 1 that led to the discovery of a superior derivative $\mathbf{7 g}$. Compound $\mathbf{7 g}$ is a novel, orally available TRK inhibitor that showed excellent in vitro potency on a panel of Larotrectinib-resistant mutants both in biochemical and cellular assays. Compound $\mathbf{7 g}$ also exhibited improved in vivo antitumor efficacy in TRK wild type and mutant fusiondriven tumor xenograft models compared to the efficacy of Larotrectinib and Selitrectinib (3). These encouraging results suggest that compound $\mathbf{7 g}$ is a promising drug candidate to pursue for development of a TRK inhibitor to overcome clinically acquired resistance to Larotrectinib.

\section{Introduction}

Tropomyosin receptor kinases (TRKs), also known as neurotrophic factor receptor kinase, are a family of three distinct isoforms, TRKA, TRKB, and TRKC, which are encoded by NTRK1, NTRK2, and NTRK3 genes, respectively ${ }^{1}$. Upon binding to their cognate neurotrophin ligands (NGF with TRKA, BDNF and NT-4/5 with TRKB, and NT-3 with TRKC), the TRK proteins dimerize and become autophosphorylated. This leads to the activation of downstream signaling cascades consisting of PLCY-PKC, PI3K-AKT, and RAS-MAPK pathways, that support the crucial processes of cell survival, growth, proliferation, and differentiation in the nervous system².

Since the first identification of NTRK1 as a proto-oncogene in colon cancer in $1982^{3}$, aberrant TRK signaling due to somatic gene mutations, splice variants, overexpression, and gene fusions has been shown to be oncogenic driver in a large variety of cancers ${ }^{4}$. Among these, NTRK fusions are the most common tumorigenic forms ${ }^{5}$. The chimeric protein tropomyosin 3 (TPM3)-TRKA that results from the fusion of the N-terminal of the normally expressed protein TPM3 to the TRKA kinase domain was first found in human colorectal cancer ${ }^{3,6}$. This fusion is similar to the EML4-ALK gene fusion seen in lung cancer ${ }^{7}$. Subsequently, multiple constitutively activated NTRK fusion forms (e.g. ETV6-TRKC, QKI-TRKB, and TPR-TRKA) have been found and established as oncogenic drivers in lung cancers (prevalence of $3.3 \%)^{8,9}$, colorectal cancers $(2.2 \%)^{8}$, glioblastomas $(2.5 \%)^{10}$, pediatric gliomas $(7.1 \%)^{10}$, thyroid cancers $(16.7 \%)^{11,12}$, and mammary analogue secretory carcinoma $(>90 \%)^{13}$. Recently, an "age- and tumoragnostic" therapy, also well-known as a basket trial, was performed in patients with tumors harbouring the identical NTRK fusion partner, has reshaped the landscape of molecular targeted cancer therapies 
and represents an important milestone in precision medicine ${ }^{14}$. Thus, targeting TRK is an attractive therapeutic strategy for a wide variety of cancers.

Currently, TRK-targeted small molecule kinase inhibitors (TRKIs), including first-generation inhibitors Larotrectinib (1) $)^{15}$ and Entrectinib (2) ${ }^{16}$ (Fig. 1), were approved by U.S. Food and Drug Administration (FDA) in 2018 and 2019, respectively, for treatment of adult and pediatric patients with solid tumors that evidencing a NTRK gene fusion. Both of these achieved striking clinical efficacy in NTRK-fusion-positive tumors, showing objective response rates (ORR) of $57-79 \%{ }^{17,18}$. However, despite the initial encouraging therapeutic response to first-generation TRK inhibitors, duration of the response is invariably limited by progressively acquired resistance ${ }^{19,20}$. The primary mechanisms for acquired resistance are found to be the secondary mutations occurring at the ATP-binding site of TRK kinase. These have been shown to involve three major regions: the solvent front (e.g., TRKA ${ }^{G 595 R}$ and a homologous TRKC ${ }^{G 623 R}$ mutation), an activation loop xDFG motif (e.g., TRKA ${ }^{\mathrm{G} 667 \mathrm{C}}$ and a homologous TRKC ${ }^{\mathrm{G} 696 \mathrm{~A}}$ ), and the so-called oncogene gatekeeper residue (e.g., TRKA $\left.{ }^{\mathrm{F} 58 \mathrm{~L}}\right)^{4}$. Data from molecular modeling studies of these residue substitutions indicate that the resulting steric hindrance may have negative effects on the binding of Larotrectinib and Entrectinib ${ }^{21}$. To address the acquired resistance to prior TRK kinase inhibition, two second-generation macrocycle TRK inhibitors were developed (shown in Fig. 1): Selitrectinib (3, from Bayer/Loxo Oncology) and Repotrectinib (4, from Turning Point Therapeutics). Encouragingly, the recent phase I/II clinical results for $\mathbf{3}$ and $\mathbf{4}$ demonstrate promising prospects to overcome the solvent front mutation-mediated acquired resistance, and may provide an effective therapeutic option for patients with tumors that progressed on larotrectinib ${ }^{20,22}$. Structurally, the conformationally constrained macrocyclic inhibitors $\mathbf{3}$ and $\mathbf{4}$ can well accommodate the bulky TRKA ${ }^{\text {G595R }}$ mutant at the solvent front without any steric clashes. However, recent clinical findings indicate that therapeutic efficacy of both drugs can be compromised by the TRKA ${ }^{\mathrm{G} 667 \mathrm{C}}$ mutant in XDFG motif, as the resulting steric hindrance between the mutant and the restricted fluorinated aromatic moieties in $\mathbf{3}$ and $\mathbf{4}$ reduce binding affinity of drugs to protein $^{23}$. To date, there are no approved drugs for treatment of patients who had developed resistance to 1 and 2 resulting from TRKs kinase secondary mutations. This situation still represents an existing "unmet clinical need". Therefore, the exploration of next-generation TRKIs with potent inhibitory activities toward multiple TRKs mutants are urgently needed.Here, guided by structure-based drug design $(\mathrm{SBDD})^{24,25}$, we produced a structural modification of the reported compound 1 by scaffold hopping on the solvent front interaction region ("head" moiety marked in blue in structure 1, Fig. 2B), followed by flexibilization and fluoroalkoxy substitution of phenylpyrrolidine ("tail" moiety marked in red in 1), leading to the discovery of the superior derivative $\mathbf{7 g}$. This compound showed excellent potency on a panel of Larotrectinib-resistant mutants both in biochemical and in cellular assays with reasonable pharmacokinetic (PK) properties in rats and dogs, in addition to improved in vivo antitumor efficacy in TRK wild type fusion-driven and TRK mutant fusion-driven tumor xenograft models. Thus, $\mathbf{7 g}$ appears to be a promising drug candidate for development as a TRK inhibitor that may overcome clinically acquired resistance to Larotrectinib. 


\section{Results}

Structure-based Optimization and Structure - Activity Relationship (SAR) Exploration. In 2015, the G595R and $\mathrm{G} 667 \mathrm{C}$ substitutions in TRKA kinase domain were first reported to be associated with acquired resistance to 2 in a patient with $L M N A-T R K A$ rearranged colorectal cancer ${ }^{19}$. Then, a novel gatekeeper F589L substitution in TRKA was identified as a well-characterized mechanism of resistance to $\mathbf{1}^{17}$. Based on the X-ray structure of TRKA (PDB ID: 4AOJ) ${ }^{26}$, we performed a molecular docking modelling study to show positions of the three forms of TRKA mutants (Fig. 2a). Our study revealed that the substitutions that represent the G595R, G667C and F589L mutations are located in the solvent front, DFG, and gatekeeper regions, respectively. In order to deliver next-generation TRK inhibitors with the potential to overcome the resistance to 1 , it was necessary to develop insight into the structural basis of the interaction of 1 with wide-type TRK and its three mutants in the above regions. Therefore, we preliminarily carried out a molecular modeling study that incorporated TRKAWT and 1 (Fig. 2c). Results illustrate that 1 have the following structural features: (1) The (S)-3-hydroxypyrrolidine-1-carboxamide moiety "head" is oriented toward the solvent front, which then forms a crucial hydrogen bond ( $\mathrm{H}$-bond) with the carbonyl of Asp596. (2) The "linker" moiety of pyrazolo[1,5-a]pyrimidine anchors to the hinge region through an essential H-bond with the NH of Met592. (3) The "tail" moiety of phenylpyrrolidine containing the chiral carbon atom (Rectus) engages in an interaction with the hydrophobic back pocket near the DFG motif, wherein the meta-fluorine atom is in close proximity to Gly667 (Figs. 2b and 2c). Further computational analysis involving the TRKA ${ }^{\mathrm{G} 595 \mathrm{R}}$ (Fig. 2d) and TRKA ${ }^{\mathrm{G} 667 \mathrm{C}}$ (Fig. 2e) mutants suggests that the substitution of the small glycine residue with the amino acid bearing additional bulk side chains (e.g., guanidyl side chain of arginine or the thiol side chain of cysteine) causes the steric clash, highlighted with a red arrow, and weakens the binding affinity of ligand to protein. There is also steric hindrance between the mutated Leu589 locus of TRKA ${ }^{\mathrm{F} 589 \mathrm{~L}}$ and pyrrole ring in the "Tail" moiety (Fig. 2f). In light of the above structural analysis, we initially imagined that the replacement of the bulky "head" moiety with a smaller substituent may avoid this steric clash and relieve stress at the Arg595 residue. To test this hypothesis, we proposed a scaffold hopping strategy to investigate a small set of novel TRK inhibitors 5 (Table 1). This compounds feature diverse substituents shown in block $C$ with both the pyrazolo[1,5a]pyrimidine framework and the phenylpyrrolidine component left intact. 
Table 1. In vitro TRKA wild type/mutants inhibitory activities of compounds 5a-f.

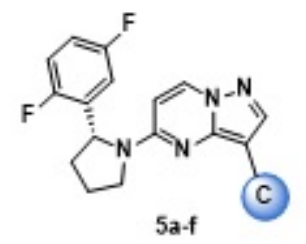

\begin{tabular}{|c|c|c|c|c|c|}
\hline \multirow{2}{*}{ Compd } & \multirow{2}{*}{ Block C } & \multicolumn{4}{|c|}{$\mathrm{IC}_{50,} \mathrm{nM}$ a } \\
\hline & & WT & G595R & G667C & F589L \\
\hline $5 a$ & & 32.1 & 28.6 & 35.0 & 147.2 \\
\hline $5 b$ & & 85.4 & 3.2 & 25.6 & 20.7 \\
\hline $5 c$ & & 298.1 & $-b$ & - & - \\
\hline $5 d$ & & 0.2 & 1.4 & 3.9 & 4.1 \\
\hline $5 e$ & & 18.1 & 3.0 & 11.6 & 23.4 \\
\hline $5 f$ & & 10.4 & 2.8 & 12.6 & 14.7 \\
\hline 1 (Larotrectinib) & & 1.2 & 109.4 & 32.2 & 43.1 \\
\hline 3 (Selitrectinib) & & 9.3 & 7.6 & 12.6 & 5.8 \\
\hline
\end{tabular}

a The potency against TRK wild-type and TRK mutants were performed using a FRET-based Z'-Lyte assay according to the manufacturer's instructions; ${ }^{b}$ Not determined; The data are the means from at least 3 independent experiments.

The kinase inhibitory activities of newly synthesized compounds 5a-f against TRKA wild type and different mutant forms of TRKA including TRKA ${ }^{G 595 R}$, TRKA ${ }^{G 667 C}$, and TRKA ${ }^{F 589 L}$, were evaluated using a validated fluorescence resonance energy transfer (FRET)-based Z'-Lyte kinase assay ${ }^{27}$. Compound $\mathbf{3}$ was served as positive control and compound 1 was used for a direct comparison. As shown in Table 1, the 3hydroxypyrrolidine-1-carboxamido group in block $C$ of structure 1 was replaced with a variety of smaller substituents, including 2-oxoimidazolidin $\mathbf{5 a}$, furan $\mathbf{5 b}$, isoxazole $\mathbf{5 c}$, pyrazole $\mathbf{5 d}$, benzene $\mathbf{5 e}$, and pyridine $\mathbf{5 f}$. As expected, compound $\mathbf{5 a}\left(\mathrm{IC}_{50}\right.$ of $\left.28.6 \mathrm{nM}\right)$ exhibited a 3.8-fold improvement in potency against TRKA ${ }^{\text {G595R }}$ relative to reference compound $\mathbf{1}$. However, $\mathbf{5}$ a did not improve the inhibitory activities against TRKA ${ }^{\text {WT }}$, TRKA ${ }^{\text {G667C }}$ and TRKA ${ }^{\mathrm{F} 589 \mathrm{~L}}$. Interestingly, the five-membered aromatic heterocyclic substitutes in Block $\mathrm{C}$ had different impacts on inhibitory potency. For instance, the pyrazole $\mathbf{5 d}$ exhibited excellent potency against TRKA ${ }^{\mathrm{WT}}$. With an $\mathrm{IC}_{50}$ value of $0.2 \mathrm{nM}$, it was 427 -fold more potent than furan $\mathbf{5 b}\left(\mathrm{IC}_{50}\right.$ of $\left.85.4 \mathrm{nM}\right)$, and 1491 -fold more potent than isoxazole $\mathbf{5 c}\left(\mathrm{IC}_{50}\right.$ of $\left.298.1 \mathrm{nM}\right)$. Importantly, $\mathbf{5 d}$ achieved inhibitory activity at low nanomolar concentrations against a panel of TRKA mutants (G595R, $\mathrm{G} 667 \mathrm{C}$, and $\mathrm{F} 589 \mathrm{~L})$, having $\mathrm{IC}_{50}$ values ranging from 1.4 to $4.1 \mathrm{nM}$. This inhibitions were approximately 
1-5- and 8-78-fold lower than that exhibited by reference drugs 3 and 1 , respectively. Although introduction of the six-membered-ring groups in $\mathbf{5 e}\left(\mathrm{IC}_{50}\right.$ of $\left.3.0 \mathrm{nM}\right)$ and $\mathbf{5 f}\left(\mathrm{IC}_{50}\right.$ of $\left.2.8 \mathrm{nM}\right)$ exhibited strong inhibition of TRKA ${ }^{G 595 R}$, they were less active against TRKA ${ }^{W T}$, TRKA ${ }^{\text {G667C }}$, and TRKA ${ }^{\text {F589L }}$ relative to compound $\mathbf{5 d}$. Because the pyrazole ring is an optimal group for block $C$ to avoid the resistance-related steric clash, and it is also a highly acceptable fragment for interacting with the solvent front region in other receptor tyrosine kinases (RTKs) ${ }^{28,29}$, we selected compound $\mathbf{5} \mathbf{d}$ as the new lead for further structural optimization.

As shown in Table 2, an array of $R^{1}, R^{2}$, and $R^{3}$ substituted pyrazolyl groups were introduced into the $C 3$ position of the pyrazolo[1,5-a]pyrimidine core. It was found that monomethyl modifications of $\mathbf{5} \mathbf{d}$ yielded compounds $\mathbf{5 g}\left(\mathrm{IC}_{50}\right.$ of $\left.0.4-9.0 \mathrm{nM}\right)$ and $\mathbf{5 h}(0.6-6.4 \mathrm{nM})$ that displayed comparable inhibitory potency to that of compound $\mathbf{5} \mathbf{d}$ against TRKA ${ }^{\mathrm{WT}}$, TRKA ${ }^{\mathrm{G} 595 \mathrm{R}}$, TRKA ${ }^{\mathrm{G} 667 \mathrm{C}}$ and TRKA ${ }^{\mathrm{F} 589 \mathrm{~L}}$. The dimethyl substituted pyrazole derivatives $\mathbf{5 i}$ and $\mathbf{5}$ j showed a slight decrease in inhibitory potency compared to the monomethyl derivative $\mathbf{5 g}$. For example, compound $\mathbf{5}$ j showed an $\mathrm{IC}_{50}$ values toward TRKA ${ }^{\mathrm{WT}}$ and TRKA $^{\text {G595R }}$ of $5.0 \mathrm{nM}$ and $5.9 \mathrm{nM}$, respectively; this is about 12 -fold less active than $\mathbf{5 g}$. Subsequently, the replacements of the $N$-methyl group in the $N-R^{3}$ position with slightly larger substituents, such as hydroxyethyl (5k), methoxyethyl (5l), or cyclopropyl (5m) groups, achieved high potency against TRKA WT/mutants. Specifically, the introduction of cyclopropyl group $(5 \mathrm{~m})$ at the $N-R^{3}$ position of pyrazole led to overall subnanomolar activities against TRKA ${ }^{W T}$, TRKA ${ }^{\text {G595R }}$ and TRKA ${ }^{\text {G667C }}$. However, in every practical sense, the binding affinity of the compounds to TRKA ${ }^{\mathrm{F} 589 \mathrm{~L}}$ had not improved compared to that of the three other forms of TRKA kinase. Furthermore, the preliminary metabolic stabilities of compounds in human liver microsome were evaluated (Table 2). Unfortunately, all selected compounds (5d, $\mathbf{5 g}, \mathbf{5 k}$ and $5 \mathrm{~m}$ ) showed high clearance with a half-life of between 3.0-44.6 min. 
Table 2. In vitro TRKA WT/mutants inhibitory activities of compounds $\mathbf{5 g}-\mathbf{m}$.

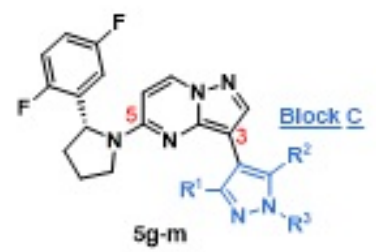

\begin{tabular}{|c|c|c|c|c|c|c|c|c|}
\hline \multirow{2}{*}{ Compd } & \multirow{2}{*}{$\mathrm{R}^{1}$} & \multirow{2}{*}{$\mathrm{R}^{2}$} & \multirow{2}{*}{$\mathrm{R}^{3}$} & \multicolumn{4}{|c|}{$\mathrm{IC}_{50}, \mathrm{nM}$} & \multirow{2}{*}{$\begin{array}{c}\text { Metabolic } \\
\text { stability } \\
\left(\mathrm{t}_{1 / 2}, \min \right)^{\circ}\end{array}$} \\
\hline & & & & TRKAWT & TRKA G595R & TRKA G66r] & TRKA $^{\text {F589L }}$ & \\
\hline $5 d$ & $\mathrm{H}$ & $\mathrm{H}$ & $\mathrm{H}$ & 0.2 & 1.4 & 3.9 & 4.1 & 44.6 \\
\hline $5 g$ & $\mathrm{H}$ & $\mathrm{H}$ & $\mathrm{Me}$ & 0.4 & 0.4 & 3.4 & 9.0 & 3.0 \\
\hline $5 \mathrm{~h}$ & $\mathrm{H}$ & $\mathrm{Me}$ & $\mathrm{H}$ & 0.6 & 6.4 & 4.6 & 2.9 & $-c$ \\
\hline $5 i$ & $\mathrm{H}$ & $\mathrm{Me}$ & $\mathrm{Me}$ & 1.2 & 6.4 & 4.6 & 10.9 & - \\
\hline $5 j$ & $\mathrm{Me}$ & $\mathrm{H}$ & Me & 5.0 & 5.9 & 1.0 & 2.7 & - \\
\hline $5 k$ & $\mathrm{H}$ & $\mathrm{H}$ & & 0.4 & 0.6 & 6.6 & 2.8 & 18.4 \\
\hline 51 & $\mathrm{H}$ & $\mathrm{H}$ & & 0.5 & 1.0 & 1.5 & 12.3 & - \\
\hline $5 \mathrm{~m}$ & $\mathrm{H}$ & $\mathrm{H}$ & $\nabla$ & 0.5 & 0.3 & 0.5 & 6.0 & 4.9 \\
\hline
\end{tabular}

a The potency against TRK wild-type and TRK mutants were performed using a FRET-based Z'-Lyte assay according to the manufacturer's instructions; ${ }^{\mathrm{b}}$ The evaluation of metabolic stability in human liver microsome; ${ }^{\mathrm{c}}$ Not determined; The data are the means from at least 3 independent experiments.

Further structural modifications were therefore completed to improve TRKA ${ }^{\mathrm{F} 589 \mathrm{~L}}$ inhibitory potency and drug-likeness. A better understanding of the subtle differences in the binding of $5 \mathrm{~m}$ to TRKA ${ }^{\mathrm{WT}}$ and TRKA ${ }^{\text {F589L }}$ could pave the way for further rational molecular design. We thus undertook additional in silico molecular modeling to explore the protein-ligand interactions in the region of the gatekeeper residue. We discovered that compound $\mathbf{5 m}$ adopts a nearly planar configuration that allows it to fit well into the ATP-binding pocket of TRKA ${ }^{\mathrm{WT}}$. The pyrrole ring moiety of $5 \mathrm{~m}$ is orthogonal to the plane of gatekeeper residue Phe589, and localizes within a distance of $4.0 \AA$ to form favorable hydrophobic interaction (Fig. 3a). However, in the mutant TRKA ${ }^{\mathrm{F} 589 \mathrm{~L}}$, the free rotation of Leu589 might be limited by the rigid pyrrole moiety due to the closer distance between them (2.3 $\AA$, Fig. $3 b)$. This constraint is believed to contribute to its 12 -fold potency loss. On the basis of the presumed structural rigidity of the pyrrole configuration, we envisage that the replacement of the pyrrole moiety by a group that introduces greater flexibility and releases this limitation might be a feasible strategy. To accomplish this, the pyrrole moiety in compound $\mathbf{5 m}$ was subjected to decyclization; this process yielded the benzylamine analogue 6a (Scheme 2).

With an $\mathrm{IC}_{50}$ value of $0.9 \mathrm{nM}$ (Table 3), compound $6 \mathbf{6}$ exhibited increased inhibition against TRKA ${ }^{\mathrm{F} 589 \mathrm{~L}}$. Nevertheless, compound 6 a suffered from a 32 -fold loss of potency against TRKA ${ }^{\mathrm{G} 667 \mathrm{C}}\left(\mathrm{IC}_{50}\right.$ value of $16.1 \mathrm{nM})$. Although the replacements of cyclopropyl in $\mathbf{6 a}$ with hydrogen (6b), methyl (6c), hydroxyethyl (6d), and methoxyethyl (6e) were well-tolerated, the damaged effectiveness of inhibition demonstrated by 
$\mathbf{6 a}$ toward TRKA ${ }^{\mathrm{G} 667 \mathrm{C}}$ was not rescued. Gratifyingly, compared with phenylpyrrole derivatives $\mathbf{5} \mathbf{d}$ and $\mathbf{5 k}$ $\left(t_{1 / 2}\right.$ of $44.6 \mathrm{~min}$ and $18.4 \mathrm{~min}$, respectively), the benzylamine derivatives $\mathbf{6 b}$ and $\mathbf{6} \mathbf{d}$ demonstrated displayed lower clearance rate in human liver microsomal ( $t_{1 / 2}$ of $119.7 \mathrm{~min}$ and $365.4 \mathrm{~min}$, respectively).

Table 3. In vitro TRKA WT/mutants inhibitory activities of compounds 6a-e.

\begin{tabular}{|c|c|c|c|c|c|c|}
\hline \multirow{2}{*}{ Compd } & \multirow{2}{*}{$\mathrm{R}^{3}$} & \multicolumn{4}{|c|}{$\mathrm{IC}_{50}, \mathrm{nM} \mathrm{a}$} & \multirow{2}{*}{$\begin{array}{c}\text { Metabolic } \\
\text { stability } \\
\left(\mathrm{t}_{1 / 2}, \min \right)^{b}\end{array}$} \\
\hline & & TRKAWT & TRKA $6595 \mathrm{~A}$ & TRKA $^{\mathrm{G} 66 \pi \mathrm{C}}$ & TRKA $^{\text {F589L }}$ & \\
\hline $5 m$ & & 0.5 & 0.3 & 0.5 & 6.0 & 4.9 \\
\hline $6 a$ & $\nabla$ & 0.6 & 0.8 & 16.1 & 0.9 & $-c$ \\
\hline $6 b$ & $\mathrm{H}$ & 0.7 & 2.5 & 25.1 & 1.1 & 119.7 \\
\hline $6 c$ & $\mathrm{Me}$ & 1.1 & 2.5 & 12.4 & 1.1 & - \\
\hline $6 \mathrm{~d}$ & $\mathrm{Or}$ & 0.6 & 1.1 & 16.7 & 0.4 & 365.4 \\
\hline $6 e$ & 0 & 1.3 & 3.9 & 32.9 & 0.5 & - \\
\hline
\end{tabular}

a The potency against TRK wild-type and TRK mutants were performed using a FRET-based Z'-Lyte assay according to the manufacturer's instructions; ' ${ }^{2}$ The evaluation of metabolic stability in human liver microsome; ${ }^{\mathrm{c}}$ Not determined; The data are the means from at least 3 independent experiments

The design goal of the next stage is to improve TRKA ${ }^{G 667 C}$ inhibitory potency, while maintaining its effectiveness against TRKA ${ }^{\mathrm{WT}}$, TRKA ${ }^{\mathrm{G} 595 \mathrm{R}}$ and TRKA ${ }^{\mathrm{F} 589 \mathrm{~L}}$ as well as to maintain the metabolic stability of $\mathbf{6 d}$. To guide further drug design efforts and rationalize the decreased potency of benzylamine derivatives (Fig. 4a), computational modeling of $\mathbf{5} \mathbf{d}$ and $\mathbf{6} \mathbf{b}$ with TRKA ${ }^{\mathrm{G} 667 \mathrm{C}}$ was performed. The model suggests that the phenylpyrrolyl moiety of $\mathbf{5} \mathbf{d}$ is directed toward the back pocket and forms satisfying hydrophobic interactions with residues Phe589, Lys544, Phe521, and Cys667. Predictably, the flexibilization of pyrrole that yields $\mathbf{6 b}$ may have led to loss of those hydrophobic interactions, that are likely responsible for the 6.4-fold reduction of inhibitory activity against the TRKA ${ }^{G 667 C}$ mutant (5d vs $\mathbf{6 b}$ ). We thus suggest it is necessary to create additional interactions to compensate for the loss of binding affinity. A further understanding of the binding mode of $6 \mathrm{~b}-\mathrm{TRKA}{ }^{\mathrm{G} 667 \mathrm{C}}$ indicates that there is a large unfilled space between the 2-F atom in the benzylamino fragment and a loop containing residues Glu518, Gly519, and Ala520 (highlighted with a red arrow, Fig. 4b). We envision that filling the space with a substituent bearing a terminal $\mathrm{H}$-bond acceptor to interact with this loop will be a useful adjustment. Therefore, we decided to screen compounds containing a set of fluoroalkoxy substituents at the C2position of the benzylamino fragment. 
As summarized in Table 4, the fluoromethoxy-substituted compound 7a exhibited good potency against TRKA $^{\mathrm{G} 667 \mathrm{C}}$ with an $\mathrm{IC}_{50}$ value of $6.1 \mathrm{nM}$, which is 4.1 -fold more potent than parent compound $\mathbf{6 b}$. Moreover, 7a displays no obvious decrements to the inhibitory potency against other types of TRK kinase. Surprisingly, compound $\mathbf{7 b}$, substituted at the $\mathrm{R}^{4}$ position with the 2-fluoroethoxy group, showed remarkably enhanced potency (25.1-fold) against TRKA ${ }^{\mathrm{G} 667 \mathrm{C}}\left(\mathrm{IC}_{50}\right.$ of $\left.1.0 \mathrm{nM}\right)$ when compared to that of 6b. In addition, $7 \mathrm{~b}$ also demonstrated the subnanomolar level inhibitory activities against TRKC ${ }^{\mathrm{G} 623 \mathrm{R}}$ and TRKC ${ }^{\text {G696A }}$. However, insertion of a methylene unit to the 2-fluoroethoxy group in $7 \mathrm{~b}$ yielded compound 7c. Compound 7c displayed a 6.3-fold reduced potency against TRKA ${ }^{\mathrm{G} 667 \mathrm{C}}\left(\mathrm{IC}_{50}\right.$ value of $\left.6.3 \mathrm{nM}\right)$. These results suggest that a chain length of 2 carbon atoms might optimally position the $\mathrm{H}$-bond acceptor to capture the residues in the TRKA ${ }^{\mathrm{G} 667 \mathrm{C}}$ mutant. Subsequently, the two double and triple H-bond acceptor groups with a chain length of 2 carbon atoms were introduced at the $\mathrm{R}^{4}$ position, the resulting compounds 7d bearing 2,2-difluoroethoxy group and 7e bearing 2,2,2-trifluoroethoxy group were equally as potent as $\mathbf{7 b}$. In particular, compound $\mathbf{7 d}$ exhibited moderate metabolic stability with half-life of 134.6 min. Furthermore, the $R^{3}$ position of $\mathbf{7 d}$ was well tolerated to methyl $(\mathbf{7 f})$, hydroxyethyl $(\mathbf{7 g})$, and cyclopropyl (7h) substituents. Encouragingly, compound $\mathbf{7 g}$, featuring hydroxyethyl substituent in $\mathrm{R}^{3}$, achieved the most potent inhibitory activities against TRKA ${ }^{\mathrm{WT}}$, TRKA ${ }^{\mathrm{G} 595 \mathrm{R}}$, TRKA ${ }^{\mathrm{G} 667 \mathrm{C}}$, TRKA ${ }^{\mathrm{F} 589 \mathrm{~L}}$, $\mathrm{TRKC}^{\mathrm{G} 623 \mathrm{R}}$, and TRKC ${ }^{\mathrm{G} 696 \mathrm{~A}}$ with $\mathrm{IC}_{50}$ values of $0.7,0.2,0.5,0.3,0.6$, and $0.3 \mathrm{nM}$, respectively, and good metabolic stability $\left(\mathrm{t}_{1 / 2}\right.$ of $\left.315.3 \mathrm{~min}\right)$. 
Table 4. In vitro TRKAWT and TRK mutants inhibitory activities of compounds 7a-h.

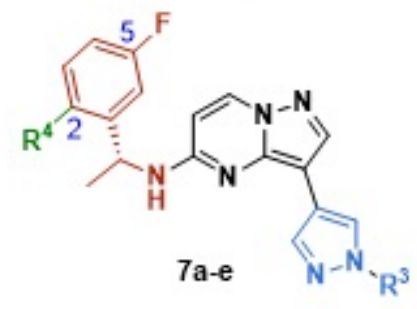

\begin{tabular}{|c|c|c|c|c|c|c|c|c|c|}
\hline \multirow{2}{*}{ Compd } & \multirow{2}{*}{$\mathrm{R}^{4}$} & \multirow{2}{*}{$R^{3}$} & \multicolumn{6}{|c|}{$\mathrm{IC}_{50, \mathrm{n}} \mathrm{nM}$ a } & \multirow{2}{*}{$\begin{array}{l}\text { Metabolic } \\
\text { stability } \\
\left(\mathrm{t}_{1 / 2}, \min \right)^{b}\end{array}$} \\
\hline & & & TRKAWT & TRKA G595R & TRKA & TRKAF5g9L & TRKCG623R & TRKC $5596 \mathrm{a}$ & \\
\hline $6 b$ & & & 0.7 & 2.5 & 25.1 & 1.1 & $-c$ & - & - \\
\hline $7 a$ & Now & H & 0.7 & 5.2 & 6.1 & 0.3 & - & - & - \\
\hline $7 b$ & $\cdots$ & $\mathrm{H}$ & 2.5 & 1.1 & 1.0 & 0.3 & 0.9 & 0.8 & - \\
\hline $7 \mathrm{c}$ & Now & $\mathrm{H}$ & 1.1 & 2.1 & 6.3 & 1.0 & - & - & - \\
\hline $7 d$ & & H & 0.4 & 0.8 & 0.8 & 0.2 & 0.5 & 0.8 & 134.6 \\
\hline $7 e$ & 。文 & $\mathrm{H}$ & 2.8 & 0.8 & 0.8 & 0.4 & 0.7 & 1.3 & - \\
\hline $7 f$ & a & $\mathrm{Me}$ & 0.5 & 1.0 & 0.9 & 0.3 & 1.7 & 0.2 & - \\
\hline $7 \mathrm{~g}$ & 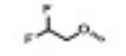 & $\mathrm{CoH}$ & 0.7 & 0.2 & 0.5 & 0.3 & 0.6 & 0.3 & 315.3 \\
\hline $7 \mathrm{~h}$ & is & $\nabla$ & 0.8 & 1.7 & 3.1 & 0.6 & 3.0 & 0.6 & - \\
\hline
\end{tabular}

a The potency against TRK wild-type and TRK mutants were performed using a FRET-based Z'-Lyte assay according to the manufacturer's instructions; ${ }^{b}$ The evaluation of metabolic stability in human liver microsome; ${ }^{\mathrm{c}}$ Not determined; The data are the means from at least 3 independent experiments.

To interpret the SAR, molecular docking studies were constructed for the most potent compound $7 \mathbf{g}$. As shown in Fig. 5A, 7g is accommodated in the active site of G595R-mutated TRKA as a "U-shaped" configuration, and makes the same backbone hinge contact as 1 due to the overlapping positions of pyrazolo[1,5-a]pyrimidine in both of them. Compared to the rigid hydroxypyrrolidine ring of $\mathbf{1}$, the flexible hydroxyethyl group of $\mathbf{7 g}$ not only indulges the free rotation of residue Arg595 without causing steric clash but also forms an $\mathrm{H}$-bond with the $\mathrm{NH}$ of Asp596. Moreover, there is an additional $\mathrm{H}$-bond between difluoroethoxy in $\mathbf{7 g}$ and $\mathrm{NH}$ of Glu518 that plays a key role in enhancing binding affinity, and supports our predictions. In the TRKA ${ }^{\mathrm{G} 667 \mathrm{C}}$ mutant (Fig. 5B), close to the solvent front region, the hydroxyl moiety of compound $\mathbf{7 g}$ forms two H-bonds with the carbonyl of Arg595 and the $\mathrm{NH}$ of Asp596, whereas a single weaker $\mathrm{H}$-bond was observed for compound 1. There is also an additional $\mathrm{H}$-bond between the difluoroethoxy moiety of $\mathbf{7 g}$ and Glu518, which might drag the flexible benzylamine fragment away from the residue $\mathrm{C} 667$ to avoid steric hindrance. However, the restricted phenylpyrrole ring in $\mathbf{1}$ is more likely to hinder the free rotation of the residue Cys667 than the phenyl-difluoroethoxy group of $\mathbf{7 g}$. The combination of the above led us to adopt $\mathbf{7 g}$ as the lead candidate, particularly because of its stronger binding affinity with TRKA ${ }^{\mathrm{G} 667 \mathrm{C}}$ as compared to 1 .

Cellular Antiproliferative Assay. In order to evaluate the suppressive effects on cellular growth of the new TRK inhibitor, we tested the most potent compound $\mathbf{7 g}$ as well as the second-generation TRK inhibitor 
Selitrectinib (3) against a panel of Ba/F3 cells stably transfected with clinically relevant ETV6-NTRK ${ }^{30-32}$ and LMNA-NTRK ${ }^{33,34}$ oncogenic fusions including ETV6-TRKA ${ }^{\text {WT }}$, ETV6-TRKB ${ }^{\text {WT }}$, ETV6-TRKC ${ }^{\text {WT }}$, LMNATRKA $^{\text {G595R }}{ }^{\text {, LMNA-TRKA }}{ }^{\text {G667C }}$, and LMNA-TRKA ${ }^{\text {F582 }}$ (Table 5). Consistent with the results of its impressive enzyme-based inhibition assays, compound $\mathbf{7 g}$ potent inhibition was also evident in the proliferation assays of $\mathrm{Ba} / \mathrm{F} 3$ cells expressing native isoforms TRKA/B/C at subnanomole concentrations ( $\mathrm{IC}_{50}$ values of $0.2,0.3$, and $0.2 \mathrm{nM}$, respectively). These $\mathrm{IC}_{50}$ values are better than the potencies of compound $\mathbf{3}$ for the same isoforms $(1.1,1.4$, and $1.6 \mathrm{nM})$. Encouragingly, $\mathbf{7 g}$ achieved 6-63fold stronger antiproliferative activities against $\mathrm{Ba} / \mathrm{F} 3$ cells transformed with Larotrectinib resistancerelevant mutants that produced $\mathrm{IC}_{50}$ values ranging from 0.2 to $10.6 \mathrm{nM}$, compared to $\mathrm{IC}_{50}$ values (12.6$72.6 \mathrm{nM}$ ) for compound 3.

Table 5. Antiproliferative activities of 3 and $7 \mathrm{~g}$ against a panel of oncogenically transfected Ba/F3 cell lines ${ }^{a}$.

\begin{tabular}{|c|c|c|}
\hline Cell models $\left(\mathrm{IC}_{50}, \mathrm{nM}\right)$ & 3 (Selitrectinib) & $7 \mathrm{~g}$ \\
\hline Ba/F3-ETV6-TRKA & 1.1 & 0.2 \\
\hline Ba/F3-ETV6-TRKBWT & 1.4 & 0.3 \\
\hline Ba/F3-ETV6-TRKCWT & 1.6 & 0.2 \\
\hline Ba/F3-LMNA-TRKA G595R & 13.0 & 1.6 \\
\hline $\mathrm{Ba} / \mathrm{F3}$-LMNA-TRKA $6667 \mathrm{C}$ & 72.6 & 10.9 \\
\hline Ba/F3-LMNA-TRKA F589L & 12.6 & 0.2 \\
\hline
\end{tabular}

a The data were means from at least three independent experiments. $I_{50}$ values were calculated by concentration-response curve fitting utilizing a four-parameter analytical method on GraphPad Prism 9.0 software.

In Vivo Antitumor Efficacy Study. Greatly encouraged by the overall promising results mentioned above, the in vivo antitumor efficacy of compound $\mathbf{7 g}$ was profiled in different mouse xenograft models harbouring Ba/F3-TMP3-TRKA ${ }^{\mathrm{WT}}$, Ba/F3-TMP3-TRKA ${ }^{\mathrm{G} 595 \mathrm{R}}$ and Ba/F3-EVT6-TRKC ${ }^{\mathrm{G} 623 \mathrm{R}}$ tumor cells. Larotrectinib (1) and Selitrectinib (3) were used as corresponding positive controls to validate the animal models. The vehicle or indicated compounds were administered orally BID after tumor volume attained $100 \sim 150 \mathrm{~mm}^{3}$ for 12-14 consecutive days. As shown in Fig. 6a, $7 \mathrm{~g}$ dose-dependently inhibited the $\mathrm{Ba} / \mathrm{F} 3-\mathrm{TMP} 3-\mathrm{TRKA}{ }^{\mathrm{WT}}$ transfected tumor progression with TGI (tumor growth inhibition) of $64 \%$ (5 mg/kg) and $85 \%(15 \mathrm{mg} / \mathrm{kg})$, whereas the reference drug 1 showed lower antitumor activities with a TGI of $70 \%$ at the same dose of $15 \mathrm{mg} / \mathrm{kg}$. Importantly, in the Larotrectinib-resistant mutants Ba/F3-TMP3TRKA $^{\text {G595R }}$ and Ba/F3-EVT6-TRKC ${ }^{\text {G623R }}$ positive xenograft mouse models (Figs. $6 \mathrm{~b}$ and $6 \mathrm{c}$ ), $\mathbf{7 g}$ also potently induced tumor growth inhibition with TGI values of $61 \%$ and $88 \%$ for the respective xenografts, at a $30 \mathrm{mg} / \mathrm{kg}$ dose. The positive control groups, which were given doses of 3 , exhibited TGls of $30 \%$ and $73 \%$ for the Ba/F3-TMP3-TRKA ${ }^{\text {G595R }}$ and Ba/F3-EVT6-TRKC ${ }^{\text {G623R }}$ xenografts at $30 \mathrm{mg} / \mathrm{kg}$ dose, 
respectively. In comparison, $\mathbf{7 g}$ achieved a better antitumor response in these two TRK mutant-dependent tumor models. In addition, no mortality and no significant loss of body weight occurred in any of the $\mathbf{7 g}$ treated groups (Fig. S1).

Chemistry. The syntheses of $\mathbf{5 a - m}$ are illustrated in Scheme 1 . The commercially available $(R)-2-(2,5-$ difluorophenyl)pyrrolidine hydrochloride $\mathbf{8}$ was reacted with 5-chloropyrazolo[1,5-a]pyrimidine to provide $\mathbf{9}$ under DIPEA in n-Butanol. This was followed by iodination with NIS and led to the key intermediate $10^{35}$. Compound 5a was prepared by a copper-catalyzed amination reaction of $\mathbf{1 0}$ with imidazolidin-2-one. Suzuki coupling of $\mathbf{1 0}$ with boronic acid pinacol ester derivatives $\mathbf{1 1}$ provided $\mathbf{5 b} \mathbf{b}$. The synthetic route of $\mathbf{6 a - e}$ was similar to that described for $\mathbf{5 b - m}$, as depicted in Scheme 2. Briefly, the key intermediate $\mathbf{1 4}$ was prepared by amination-iodination reactions of commercially available $(R)$-1-(2,5-difluorophenyl)ethan-1amine hydrochloride 12. Suzuki coupling of $\mathbf{1 4}$ with different boronic acid pinacol esters 15 provided 6ae. Compounds 7a-h were prepared according to the procedures outlined in Scheme 3. The starting compound 16 was treated with 5-chloropyrazolo[1,5-a]pyrimidine under DIPEA in n-Butanol, and the resulting compound $\mathbf{1 7}$ was then deprotected with TFA to obtain the phenol $\mathbf{1 8}$. The key intermediates $19 a-e$ were successfully yielded by alkylation-iodination reactions of $\mathbf{1 8}$. The target compounds $7 \mathrm{a}-\mathrm{h}$ were prepared from 19a-c via Suzuki coupling with different boronic acid pinacol esters 15 .

Table 6. Pharmacokinetic properties of Compound $7 \mathrm{~g}$ in rats and beagle dogs.

\begin{tabular}{|c|c|c|c|c|}
\hline \multirow{3}{*}{$\frac{7 \mathrm{~g}}{\text { Parameter }^{\mathrm{c}}}$} & \multicolumn{2}{|c|}{ SD rats ${ }^{a}$} & \multicolumn{2}{|c|}{ Beagle dogs ${ }^{b}$} \\
\hline & $1 \mathrm{mg} / \mathrm{kg}$ & $5 \mathrm{mg} / \mathrm{kg}$ & $1 \mathrm{mg} / \mathrm{kg}$ & $5 \mathrm{mg} / \mathrm{kg}$ \\
\hline & (i.v.) & (i.g.) & (i.v.) & (i.g.) \\
\hline$T_{1 / 2}(\mathrm{~h})$ & 5.7 & 5.7 & 7.2 & 6.28 \\
\hline$T_{\max }(\mathrm{h})$ & - & 0.25 & - & 0.83 \\
\hline$C_{\max }(\mathrm{ng} / \mathrm{mL})$ & 104.1 & 217.7 & 1497.8 & 1570.3 \\
\hline $\mathrm{AUC}_{0 \infty}(\mathrm{h} \cdot \mathrm{ng} / \mathrm{mL})$ & 212.8 & 540.5 & 2140.0 & 9627.5 \\
\hline$V_{z}(\mathrm{~L} / \mathrm{kg})$ & 40.0 & 79.26 & 4.94 & 4.77 \\
\hline $\mathrm{CL}(\mathrm{L} / \mathrm{h} / \mathrm{kg})$ & 5.0 & 9.5 & 0.47 & 0.55 \\
\hline$F(\%)$ & - & 49.3 & - & 91.9 \\
\hline
\end{tabular}

a Vehicle i.v.: $70 \%$ PEG400 + 30\% Saline; i.g.: 0.5\% CMC-Na + 1\% Tween $80+98.5$ water. ${ }^{b}$ i.v. and i.g.: $5 \%$ DMA $+10 \%$ Solutol $+85 \%$ Saline. $T_{1 / 2}$, half-life; $T_{\max ,}$ time of maximum concentration; $C_{\max ,}$ maximum concentration; $\mathrm{AUC}_{0-\ldots,}$, area under the plasma concentration time curve; $\mathrm{V}_{\mathrm{Z}}$, volume of distribution; $\mathrm{CL}$, clearance; $F$, oral bioavailability. ${ }^{\mathrm{c}}$ Data reported as the average of three animals.

\section{Discussion}


Clinically acquired resistance caused by secondary mutations within the ATP-binding pocket represents a common mechanism and a major "unmet clinical need" in targeted cancer therapy. Similar to mutations found in $\mathrm{ALK}^{36,37}$ and $\mathrm{RET}^{38}$, the most frequent secondary mutations in TRKs appear at the solvent front TRKA $^{\text {G595R }}$ and TRKC ${ }^{\text {G623R }}$, the XDFG motif TRKA ${ }^{\text {G667C }}$ and TRKC ${ }^{\text {G696A }}$, and the gatekeeper TRKA ${ }^{\text {F589L. }}$. Mutations at these loci confer confer resistance to FDA-approved first-generation TRK inhibitors Larotrectinib (1) ${ }^{20}$ and Entrectinib (2) ${ }^{19}$. Although the second-generation inhibitors Selitrectinib (3) and Repotrectinib (4) potently inhibit the majority of larotrectinib-resistant mutations via a macrocyclization approach, they cannot effectively overcome the XDFG motif TRKA ${ }^{\mathrm{G} 667 \mathrm{C}}$ and TRKC ${ }^{\mathrm{G} 696 \mathrm{~A} 23}$. To date, there are no options with TRKIs are clinically available for treatment of Larotrectinib- and Entrectinib-refractory patients. Identifying a next-generation inhibitor that overcomes multiple TRK-resistant mutations is therefore of supreme clinical relevance.

In this study, by modifying the reported TRK inhibitor 1, we developed a novel inhibitor library for various mutant forms of TRK by applying SBDD, paying special attention to mutantions in the solvent front (led to compounds 5), the gatekeeper element (compounds 6), and modification of substituents $R^{4}$ (compounds 7). After three rounds of SAR exploration, one of the most promising compounds $\mathbf{7 g}$ was identified; it exhibited subnanomolar activities ( $\mathrm{IC}_{50}$ of $0.2-0.7 \mathrm{nM}$ ) against a panel of aforementioned TRK resistance mutations. In addition, $\mathbf{7 g}$ exhibited strong antiproliferative activities against Ba/F3 cells transformed with native TRKA/B/C isoforms and various TRK mutants. Importantly, $\mathbf{7 g}$ showed favorable in vitro metabolic stability in human liver microsome ( $\mathrm{t}_{1 / 2}$ of $\left.315.3 \mathrm{~min}\right)$ and in vivo PK profiles in SD rats $(F=49.3 \%)$ and Beagle dogs $(F=91.9 \%)$. A further in vivo efficacy studies in mouse xenograft models indicated that $\mathbf{7 g}$ significantly suppressed the growth of tumors driven by native TMP3-TRKA (TGI of $85 \%$ at $15 \mathrm{mg} / \mathrm{kg}$ ), TMP3-TRKA ${ }^{\text {G595R }}$ (TGI of $61 \%$ at $30 \mathrm{mg} / \mathrm{kg}$ ), and EVT6-TRKC ${ }^{\text {G623R }}$ (TGI of $88 \%$ at 30 $\mathrm{mg} / \mathrm{kg}$ ).All $\mathbf{7 g}$ tumor inhibition results were found to be superior to those produced by Larotrectinib (TGI of $70 \%$ at $15 \mathrm{mg} / \mathrm{kg}$ ) and Selitrectinib (TGI of $30 \%$ and $73 \%$ at $30 \mathrm{mg} / \mathrm{kg}$, respectively). Collectively, the potential for the novel TRK inhibitor $\mathbf{7 g}$ to overcome the common TRK mutations that contribute to Larotrectinib resistance suggests that it is a promising drug candidate for further development.

\section{Methods}

General Chemistry. Unless otherwise noted, reagents and solvents used in experiments were purchased from commercial sources and used without further purification. Flash chromatography was performed using 200-400 Mesh silica gel from Qingdao Makall Group Co., Ltd.; China. Silica gel plates-based thinlayer chromatography (TLC) was used to monitor all reactions with fluorescence F254 or F365 light. the reactions involving air- or moisture-sensitive reagents were performed under a nitrogen or argon atmosphere. ${ }^{1} \mathrm{H}$ NMR spectra (400 or $600 \mathrm{MHz}$ ) and ${ }^{13} \mathrm{C}$ NMR (100 or $150 \mathrm{MHz}$ ) spectra were recorded on a Bruker BioSpin AG (Ultrashield Plus AV $400 \mathrm{M}$ or $600 \mathrm{M}$ ) spectrometer as deuterochloroform $\left(\mathrm{CDCl}_{3}\right)$ or dimethyl sulfoxide- $d_{6}\left(\right.$ DMSO- $d_{6}$ ) solutions using tetramethylsilane (TMS) as an internal standard $(\delta=0)$ unless noted otherwise. In the tabulated NMR results, $s$ indicates singlet; br, broad singlet; $d$; doublet; $t$, triplet; q, quartet; m, multiplet; dd, doublet of doublet. The purities of all target compounds were 
determined to be $>95 \%$ by highperformance liquid chromatography (HPLC). HPLC conditions were as follows: Gemini C18 column at room temperature, $4.6 \mathrm{~cm} \times 150 \mathrm{~cm}, 5 \mu \mathrm{m}, 10-90 \%$ acetonitrile $(0.05 \%$ TFA)/water (0.05\% TFA), $10 \mathrm{~min}$ run; flow rate, $1 \mathrm{~mL} / \mathrm{min}$; UV detection $\lambda=214 \mathrm{~nm}, 254$, and $280 \mathrm{~nm}$. MS spectra were obtained on an agilent technologies 6120 quadrupole LC/MS (ESI). High-resolution mass spectra (HR-MS) were obtained on an Agilent 6224 TOF LC/MS (USA). Yields were of purified compounds and were not optimized.

In vitro enzymatic activity assay. The inhibitory activities of the compounds against native TRK and TRK mutants (Invitrogen) were determined using a fluorescence resonance energy transfer (FRET)-based Z'Lyte kinase assay assay system following to the manufacturer's instructions. Briefly, TRKA ( $3 \mathrm{nM})$ in the enzymatic buffer solutions (1* assay buffer (cisbio) with $5 \mathrm{mM} \mathrm{MgCl}_{2}, 1 \mathrm{mM} \mathrm{DTT}$ ) were mixed with various concentrations of inhibitors and incubated for 30 minutes at $25^{\circ} \mathrm{C}$. Subsequently a mixture of TKSub-biotin peptide and ATP was added to initiate assay with the final peptide and ATP concentrations at $0.5 \mu \mathrm{M}$ and $100 \mu \mathrm{M}$, respectively. The reaction mixture was incubated for 40 minutes at $25^{\circ} \mathrm{C}$, afterwards TK antibody and XL665 in detection buffer (cisbio) was added to stop assay and the mixture was incubated at $25^{\circ} \mathrm{C}$ for 60 minutes. The FRET signal (665/615 ratio) was measured on Envision (PerkinElmer).

Human Microsomal Stability Studies. The in vitro metabolic stabilities of selected compounds were performed using human liver microsomes in triplicate. The buffer used in this study was $100 \mathrm{mM}$, phosphate buffer with $3.3 \mathrm{mM} \mathrm{MgCl}_{2}$. The incubation mixtures containing $0.5 \mathrm{mg} / \mathrm{mL}$ human liver microsomes and test compounds $(1 \mu \mathrm{M})$ in $100 \mathrm{mM}$ potassium phosphate buffer. The reaction was initiated by addition of $80 \mu \mathrm{L}$ of the NADPH regenerating system to $320 \mu \mathrm{L}$ of each incubation mixture. The final incubation conditions achieved in $400 \mu \mathrm{L}$ are: $0.5 \mathrm{mg} / \mathrm{mL}$ human liver microsomes, $1 \mu \mathrm{M}$ test compounds, $1.3 \mathrm{mM} \mathrm{NADPH}, 3.3 \mathrm{mM}$ glucose 6 phosphate, $0.6 \mathrm{U} / \mathrm{mL}$ glucose 6 phosphate dehydrogenase. The mixtures were incubated in a $37^{\circ} \mathrm{C}$ water bath with gentle shaking. A $100 \mu \mathrm{L}$ aliquot of each mixture was removed at 10,30, 90 minutes to a clean 96-well plate which contains $400 \mu \mathrm{L}$ quench reagent to precipitate proteins, and centrifuged $(5000 \times \mathrm{g}, 15 \mathrm{~min}) .80 \mu \mathrm{L}$ of supernatant are taken into 96-well assay plates pre-added with $160 \mu \mathrm{L}$ ultrapure water, and then analyzed by LC-MS/MS.

Molecular Docking. The three-dimension (3D) structures of small molecules were prepared by using SYBYL 7.0 followed by 3,000 steepest descent minimization and 3,000 conjugate gradient minimization, respectively. The X-ray structure of wild-type (WT) TRK (PDB 4AOJ) was obtained from the Protein Data Bank (PDB, http://www.pdb.org). The original ligand in the protein was used as the reference to define the active site. The hydrogens of the receptor were added by using Discovery Studio 4.0. The GOLD 3.0 ${ }^{39}$ was used to dock each small molecule into the active center. The radius of active site was set to $10 \AA$ by using a genetic algorithm (GA) with 300 runs. GoldScore was used to evaluate the binding affinity and the top rank conformation was selected as the representative.

Computational Mutation Analysis. The Site-Specific Mutation Module in Auto In silico Macromolecule Mutation Scanning (AIMMS) server (http://chemyang.ccnu.edu.cn/ccb/server/AIMMS/index.php) ${ }^{40}$ was 
used to quantitatively evaluate the effects of TRK mutants (G595R, G667C, F589L) towards our compounds. The complex structures of WT TRK binding with different compounds, obtained from docking result, were used as the input for AIMMS server. The binding mode of the mutant-type (MT) TRK with our compounds were obtained by using the combination of sidechain replacement and molecular dynamics (MD) simulation in AIMMS. The binding free energy $(\Delta G)$ for both wild type (WT) and mutant type (MT) were then calculated according to the MM_PBSA method ${ }^{41}$. Detailed calculation method can be found in our previous study of AIMMS $^{40}$.

Cell Proliferation Assays. Ba/F3 cells expressing ETV6-TRKAWT, ETV6-TRKB WT, ETV6-TRKCWT, LMNATRKA $^{\text {G595R }}$, LMNA-TRKA ${ }^{\text {G667C }}$, and LMNA-TRKA ${ }^{\text {F589L }}$ were cultured in RPMI medium 1640 supplemented with $10 \%$ fetal bovine serum (FBS) at $37^{\circ} \mathrm{C}$ in the air containing $5 \% \mathrm{CO}_{2}$ atmosphere. The cell proliferation inhibitory activities of $\mathrm{Ba} / \mathrm{F} 3$ cell lines were determined according to the reported method ${ }^{42,43}$. Cells were seeded in 96 -well plates $\left(0.5 \times 10^{5}\right.$ cells/well). Twenty-four hours later, compounds $7 \mathrm{~g}$ or 3 were added to the designated wells, and cells were incubated at $37^{\circ} \mathrm{C}$ for additional $72 \mathrm{~h}$. After the treatment above, CCK-8 was added into the 96 -well plates $(10 \mu \mathrm{L} /$ well $)$ and incubated with the cells for $3 \mathrm{~h}$. OD 450 and OD650 were determined by a microplate reader. Absorbance rate (A) for each well was calculated as OD 450 - OD650. The cell viability rate for each well was calculated as $V \%=(A s-A c) /(A b-A c) \times 100 \%$.

The data are the means from 3 independent experiments. As is the absorbance rate of the test compound well, $A c$ is the absorbance rate of the well without either cell or test compound, and $A b$ is the absorbance rate of the well with cell and vehicle control. $\mathrm{IC}_{50}$ values were calculated by concentration - response curve fitting utilizing a four-parameter analytical method on GraphPad Prism 9.0 software.

Determination of pharmacokinetic profiles in rats. The pharmacokinetic parameters of compound $\mathbf{~ g g}$ were subjected to PK studies on male SD rats (provided by Beijing Vital River Laboratory Animal Technology Co., Ltd.) weighing 180-200 g with three animals in each group. The tested compound $7 \mathrm{~g}$ [a solution of $70 \%$ PEG $400+30 \%$ Saline (i.v.) or $0.5 \% \mathrm{CMC}-\mathrm{Na}+1 \%$ Tween $80+98.5$ water (i.g.)] administered to male SD rats at a dose of $1 \mathrm{mg} / \mathrm{kg}$ (i.v.) or $5 \mathrm{mg} / \mathrm{kg}$ (i.g.). Blood samples $(0.3 \mathrm{~mL})$ were collected at the point including $5 \mathrm{~min}, 15 \mathrm{~min}, 30 \mathrm{~min}, 1 \mathrm{~h}, 2 \mathrm{~h}, 4 \mathrm{~h}, 8 \mathrm{~h}$, and $24 \mathrm{~h}$ (i.v.) or $15 \mathrm{~min}, 30 \mathrm{~min}, 1$ h, 2 h, 4 h, 8 h, and $24 \mathrm{~h}$ (i.g.) after administration, respectively, and centrifuged at $8000 \mathrm{rpm}$ for $5 \mathrm{~min}$ at 4 ${ }^{\circ} \mathrm{C}$, and then analyzed after protein precipitation. To obtain the best sensitivity and selectivity of the analyte, the LC/MS/MS analysis of compound $7 \mathbf{g}$ was carried out under optimized conditions in SRM (selected reaction monitoring) mode containing an internal standard. Plasma concentration-time data were measured by a noncompartmental approach using the software WinNonlin Enterprise, version 5.2 (Pharsight Co., Mountain View, CA).

Determination of pharmacokinetic profiles in beagle dogs. The pharmacokinetic parameters of compound $\mathbf{7 g}$ were subjected to PK studies on male beagle dogs (Provided by Beijing Marshall Biotechnology Co., Ltd.) weighing $10 \mathrm{~kg}$ with three animals in each group. The tested compound $\mathbf{7 g}$ (a solution of $5 \% \mathrm{DMA}+10 \%$ Solutol $+85 \%$ Saline) was administered to male beagle dogs at dose of 1 $\mathrm{mg} / \mathrm{kg}$ (i.v.) or $5 \mathrm{mg} / \mathrm{kg}$ (i.g.). Blood samples $(1 \mathrm{~mL}$ ) were collected before the dosage and at $5 \mathrm{~min}, 15$ 
min, 30 min, 1 h, 2 h, 4 h, 8 h, and 24 h (i.v.) or 15 min, 30 min, 1 h, 2 h, 4 h, 8 h, and 24 h (i.g.) after administration and centrifuged to separate plasma. The separated plasma was transferred into 96-well plates and kept frozen $\left(<-60^{\circ} \mathrm{C}\right)$ until LC/MS/MS detection.

In vivo antitumor activity assay. Ba/F3 cells expressing TPM3-TRKA ${ }^{\text {WT }}$ or TPM3-TRKA ${ }^{\text {G595R }}$ or ETV6TRKA $^{\text {G623R }}$ were cultured in RPMI medium 1640 supplemented with $10 \%$ fetal bovine serum (FBS) at $37^{\circ} \mathrm{C}$ in the air containing $5 \% \mathrm{CO}_{2}$ atmosphere. The resulting Ba/F3-TPM3-TRKA WT or Ba/F3-TPM3-TRKA ${ }^{\text {G595R }}$ or Ba/F3-ETV6-TRKA ${ }^{\text {G623R }}$ cells $\left(2 \times 10^{6}\right.$ cells/mouse) were injected subcutaneously in 6-week-old BALB/cA nude mice (provided by Shanghai Jihui Experimental Animal Breeding Co., Ltd.). When the size of the tumor reached about $100-150 \mathrm{~mm}^{3}$, the mice were randomly divided into vehicle group and treated group (six mice/group). Compound 7g, Larotrectinib (1) and Selitrectinib (3) were dissolved in a vehicle containing 70\% PEG400 and 30\% water. For antitumor efficacy studies, mice were dosed twice daily by p.o. administration with vehicle or inhibitors with the indicated 5 or 15 or $30 \mathrm{mg} / \mathrm{kg}$ for 12-14 consecutive days. The sizes of the tumors were measured 3 times per week using a microcaliper. The tumor volume $\left(T V=\left(\right.\right.$ length $\times$ width $\left.\left.^{2}\right) / 2\right)$ for the indicated days is the median tumor volume in each group (+ SEM). The percentage of tumor growth inhibition (\%TGI = [1-(TV inhibitor-treated_final day $_{-}$ $\left.\left.\left.T V_{\text {inhibitor-treated_day } 1}\right) /\left(T V_{\text {vehicle_treated_final day }}-T_{\text {vehicle_treated_day } 1}\right)\right] \times 100 \%\right)$ was used to evaluate the antitumor efficacy of the compounds. Tumor volumes were statistically analyzed using Student's $t$ test.

\section{Declarations}

\section{Declarations}

\section{Competing interests}

The authors declare no competing interests.

\section{Author contributions}

L.Z., M.W.,W.H., and G.Y. conceived and designed the experiments; L.Z., M.W., H.X., Y.G., Z.Y., Y.T. and C.P. performed synthesis; L.Z., M.W. and H.X. performed biological work; F.W. and G.H. performed molecular modelling; W.H., and G.Y. analyzed the data; L.Z., W.H. and N.S. wrote the paper. W.H., and G.Y. were responsible for the correspondence of the manuscript. All authors discussed, edited and approved the final version.

\section{Acknowledgments}

This work was supported by the National Key Research and Development Program of China (No. 2017YFA0505200), the Key Research and Development Program of Hubei Province, China (2020BCB042), 
the Science and Technology Program of Wuhan (No. 2019020701011460), the China Postdoctoral Science Foundation (2020M672390).

\section{References}

1. Huang, E. J. \& Reichardt, L. F. Trk receptors: Roles in neuronal signal transduction. Annu. Rev. Biochem. 72, 609-642 (2003).

2. Skerratt, S. E. et al. The Discovery of a Potent, Selective, and Peripherally Restricted Pan-Trk Inhibitor (PF-06273340) for the Treatment of Pain. J. Med. Chem. 59, 10084-10099 (2016).

3. Pulciani, S. et al. Oncogenes in solid human tumours. Nature 300, 539-542 (1982).

4. Cocco, E., Scaltriti, M. \& Drilon, A. NTRK fusion-positive cancers and TRK inhibitor therapy. Nat. Rev. Clin. Oncol. 15, 731-747 (2018).

5. Vaishnavi, A., Le, A. T. \& Doebele, R. C. TRKing Down an Old Oncogene in a New Era of Targeted Therapy. Cancer Discovery 5, 25-34 (2015).

6. Ardini, E. et al. The TPM3-NTRK1 rearrangement is a recurring event in colorectal carcinoma and is associated with tumor sensitivity to TRKA kinase inhibition. Mol. Oncol. 8, 1495-1507 (2014).

7. Takeuchi, K. et al. RET, ROS1 and ALK fusions in lung cancer. Nat. Med. 18, 378-381 (2012).

8. Stransky, N. et al. The landscape of kinase fusions in cancer. Nat. Commun. 5, 4846 (2014).

9. Vaishnavi, A. et al. Oncogenic and drug-sensitive NTRK1 rearrangements in lung cancer. Nat. Med. 19, 1469-1472 (2013).

10. Frattini, V. et al. The integrated landscape of driver genomic alterations in glioblastoma. Nat. Genet. 45, 1141-1149 (2013).

11. Greco, A., Miranda, C. \& Pierotti, M. A. Rearrangements of NTRK1 gene in papillary thyroid carcinoma. Mol. Cell. Endocrinol. 321, 44-49 (2010).

12. Kralik, J. M. et al. Characterization of a newly identified ETV6-NTRK3 fusion transcript in acute myeloid leukemia. Diagn. Pathol. 6, 19 (2011).

13. Drilon, A. et al. What hides behind the MASC: clinical response and acquired resistance to entrectinib after ETV6-NTRK3 identification in a mammary analogue secretory carcinoma (MASC). Ann. Oncol. 27, 920-926 (2016).

14. Seligson, N. D. et al. Developing Drugs for Tissue-Agnostic Indications: A Paradigm Shift in Leveraging Cancer Biology for Precision Medicine. Clin. Pharmacol. Ther. 109, 334-342 (2021).

15. Doebele, R. C. et al. An Oncogenic NTRK Fusion in a Patient with Soft-Tissue Sarcoma with Response to the Tropomyosin-Related Kinase Inhibitor LOXO-101. Cancer Discovery 5, 1049-1057 (2015).

16. Menichincheri, M. et al. Discovery of Entrectinib: A New 3-Aminoindazole As a Potent Anaplastic Lymphoma Kinase (ALK), c-ros Oncogene 1 Kinase (ROS1), and Pan-Tropomyosin Receptor Kinases (Pan-TRKs) inhibitor. J. Med. Chem. 59, 3392-3408 (2016). 
17. Drilon, A. et al. Efficacy of Larotrectinib in TRK Fusion-Positive Cancers in Adults and Children. $N$. Engl. J. Med. 378, 731-739 (2018).

18. Doebele, R. C. et al. Entrectinib in patients with advanced or metastatic NTRK fusion-positive solid tumours: integrated analysis of three phase 1-2 trials. Lancet Oncol. 21, 271-282 (2020).

19. Russo, M. et al. Acquired Resistance to the TRK Inhibitor Entrectinib in Colorectal Cancer. Cancer Discovery 6, 36-44 (2016).

20. Drilon, A. et al. A Next-Generation TRK Kinase Inhibitor Overcomes Acquired Resistance to Prior TRK Kinase Inhibition in Patients with TRK Fusion-Positive Solid Tumors. Cancer Discovery 7, 963-972 (2017).

21. Yan, W. et al. Insights into Current Tropomyosin Receptor Kinase (TRK) Inhibitors: Development and Clinical Application. J. Med. Chem. 62, 1731-1760 (2019).

22. Drilon, A. et al. Repotrectinib (TPX-0005) Is a Next-Generation ROS1/TRK/ALK Inhibitor That Potently Inhibit ROS1/TRK/ALK Solvent-Front Mutations. Cancer Discovery 8, 1227-1236 (2018).

23. Cocco, E. et al. TRK xDFG Mutations Trigger a Sensitivity Switch from Type I to II Kinase Inhibitors. Cancer Discovery 11, 126-141 (2021).

24. Bancet, A. et al. Fragment Linking Strategies for Structure-Based Drug Design. J. Med. Chem. 63, 11420-11435 (2020).

25. Cheng, H. et al. Structure-Based Drug Design and Synthesis of PI3K alpha-Selective Inhibitor (PF06843195). J. Med. Chem. 64, 644-661 (2021).

26. Wang, T. et al. Discovery of Disubstituted Imidazo[4,5-b]pyridines and Purines as Potent TrkA Inhibitors. ACS Med. Chem. Lett. 3, 705-709 (2012).

27. Rodems, S. M. et al. A FRET-based assay platform for ultra-high density drug screening of protein kinases and phosphatases. Assay Drug Dev. Technol. 1, 9-19 (2002).

28. Cui, J. J. et al. Structure Based Drug Design of Crizotinib (PF-02341066), a Potent and Selective Dual Inhibitor of Mesenchymal-Epithelial Transition Factor (c-MET) Kinase and Anaplastic Lymphoma Kinase (ALK). J. Med. Chem. 54, 6342-6363 (2011).

29. Hatcher, J. M. et al. Discovery of Inhibitors That Overcome the G1202R Anaplastic Lymphoma Kinase Resistance Mutation. J. Med. Chem. 58, 9296-9308 (2015).

30. Knezevich, S. R. et al. A novel ETV6-NTRK3 gene fusion in congenital fibrosarcoma. Nat. Genet. 18, 184-187 (1998).

31. Wu, G. et al. The genomic landscape of diffuse intrinsic pontine glioma and pediatric non-brainstem high-grade glioma. Nat. Genet. 46, 444-450 (2014).

32. Zheng, Z. et al. Anchored multiplex PCR for targeted next-generation sequencing. Nat. Med. 20, 1479-1484 (2014).

33. Wiesner, T. et al. Kinase fusions are frequent in Spitz tumours and spitzoid melanomas. Nat. Commun. 5, 3116 (2014). 
34. Sartore-Bianchi, A. et al. Sensitivity to Entrectinib Associated With a Novel LMNA-NTRK1 Gene Fusion in Metastatic Colorectal Cancer. J. Natl. Cancer Inst. 108, djv306 (2016).

35. Haas, J. et al. Substituted pyrazolo[1,5-a]pyrimidine compounds as Trk kinase inhibitors and their preparation and use in the treatment of diseases. WO 2010048314A1 (2010).

36. Choi, Y. L. et al. EML4-ALK Mutations in Lung Cancer That Confer Resistance to ALK Inhibitors. N. Engl. J. Med. 363, 1734-1739 (2010).

37. Friboulet, L. et al. The ALK Inhibitor Ceritinib Overcomes Crizotinib Resistance in Non-Small Cell Lung Cancer. Cancer Discovery 4, 662-673 (2014).

38. Drilon, A. et al. Targeting RET-driven cancers: lessons from evolving preclinical and clinical landscapes. Nat. Rev. Clin. Oncol. 15, 151-167 (2018).

39. Verdonk, M. L. et al. Improved protein-ligand docking using GOLD. Proteins 52, 609-623 (2003).

40. Wu, F. X. et al. AIMMS suite: a web server dedicated for prediction of drug resistance on protein mutation. Briefings Bioinf. 21, 318-328 (2020).

41. Kollman, P. A. et al. Calculating structures and free energies of complex molecules: Combining molecular mechanics and continuum models. Acc. Chem. Res. 33, 889-897 (2000).

42. Ren, X. et al. Identification of GZD824 as an Orally Bioavailable Inhibitor That Targets Phosphorylated and Nonphosphorylated Breakpoint Cluster Region-Abelson (Bcr-Abl) Kinase and Overcomes Clinically Acquired Mutation-Induced Resistance against Imatinib. J. Med. Chem. 56, 879-894 (2013).

43. Duan, Y. et al. Design, synthesis, and Structure-Activity Relationships (SAR) of 3-vinylindazole derivatives as new selective tropomyosin receptor kinases (Trk) inhibitors. Eur. J. Med. Chem. 203, 112552 (2020).

\section{Figures}
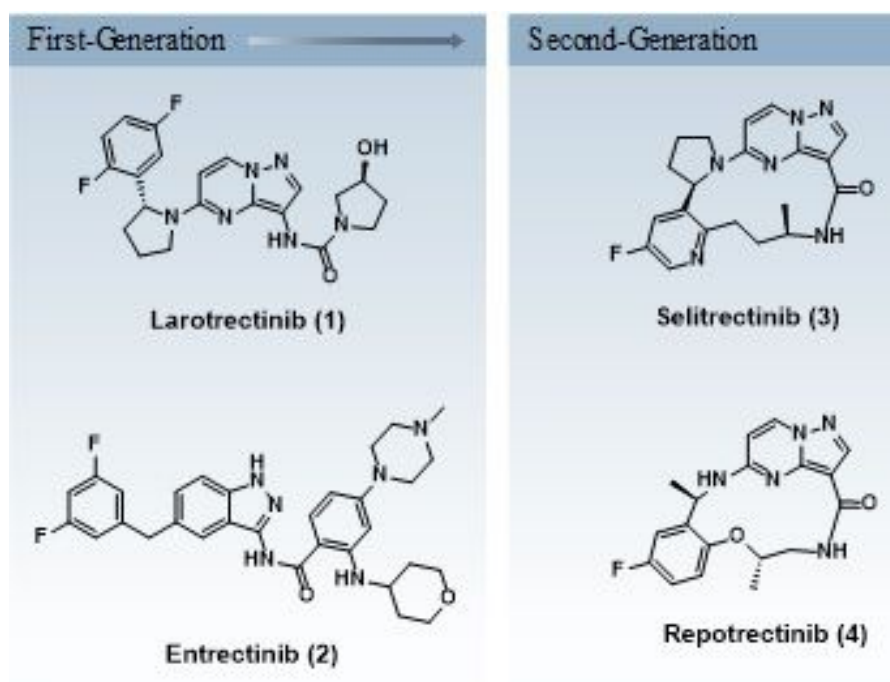

Figure 1 
Molecular structures of first- and second-generation TRK inhibitors.
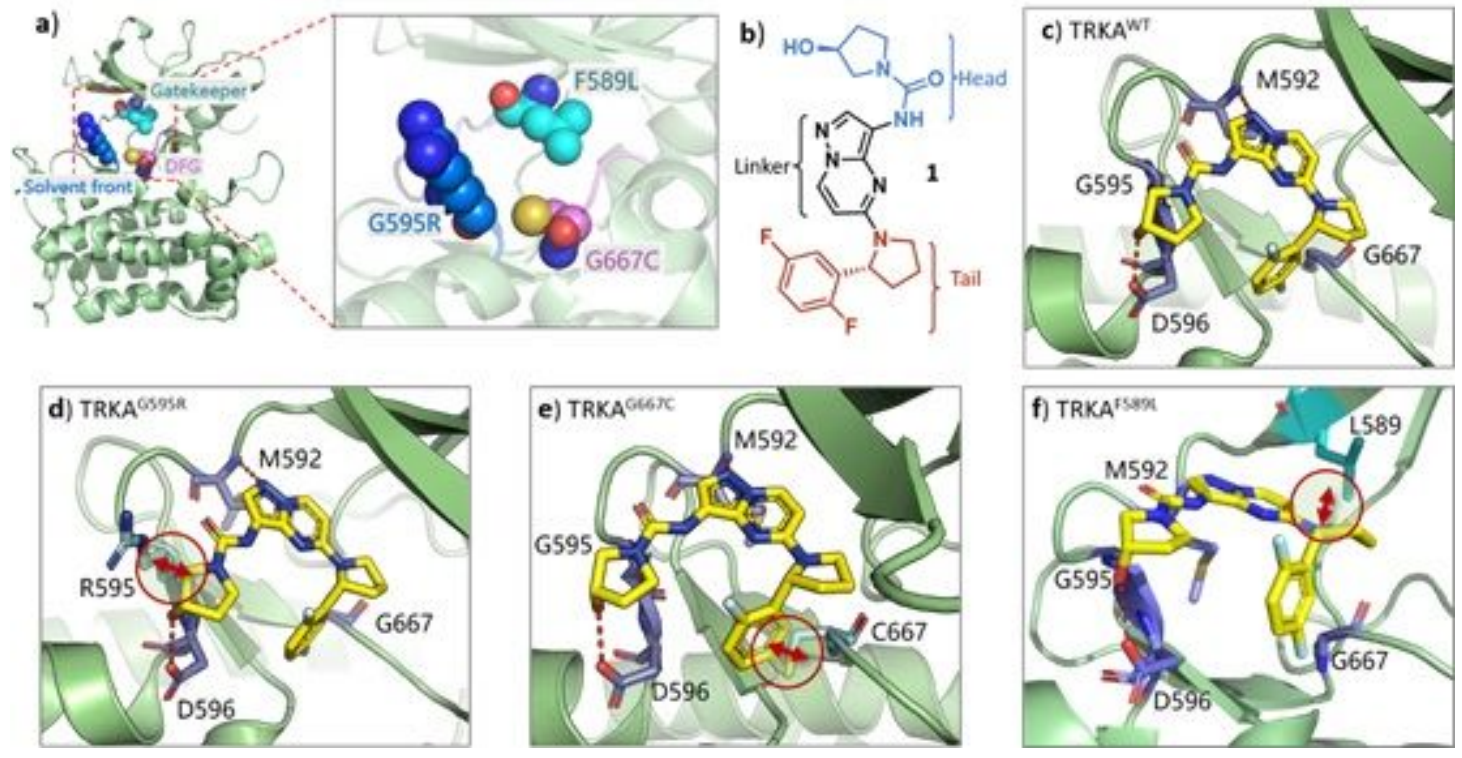

Figure 2

(a) Structural analysis of amino acid substitutions in the TRKA kinase domain: the G595R solvent- front substitutions (marine); G667C substitution within the XDFG- motif (violet); and F589L gatekeeper mutation (cyan). (b) Structural features of compound 1 including "head" ((S)-3-hydroxypyrrolidine-1carboxamide moiety), "linker" (pyrazolo[1,5-a]pyrimidine), and "tail" (phenylpyrrolidine) fragments. (c) Proposed binding model of 1 (yellow stick) bound to TRKAWT. (d) Proposed binding and steric interaction of 1 with the TRKAG595R. (e) Proposed binding and steric interaction of 1 with the TRKAG667C. ( $f$ ) Proposed binding and steric interaction of 1 with the TRKAF589L. The identified residues are shown in stick form. The H-bonds are depicted as red dashed lines. (PDB ID: 4AOJ)
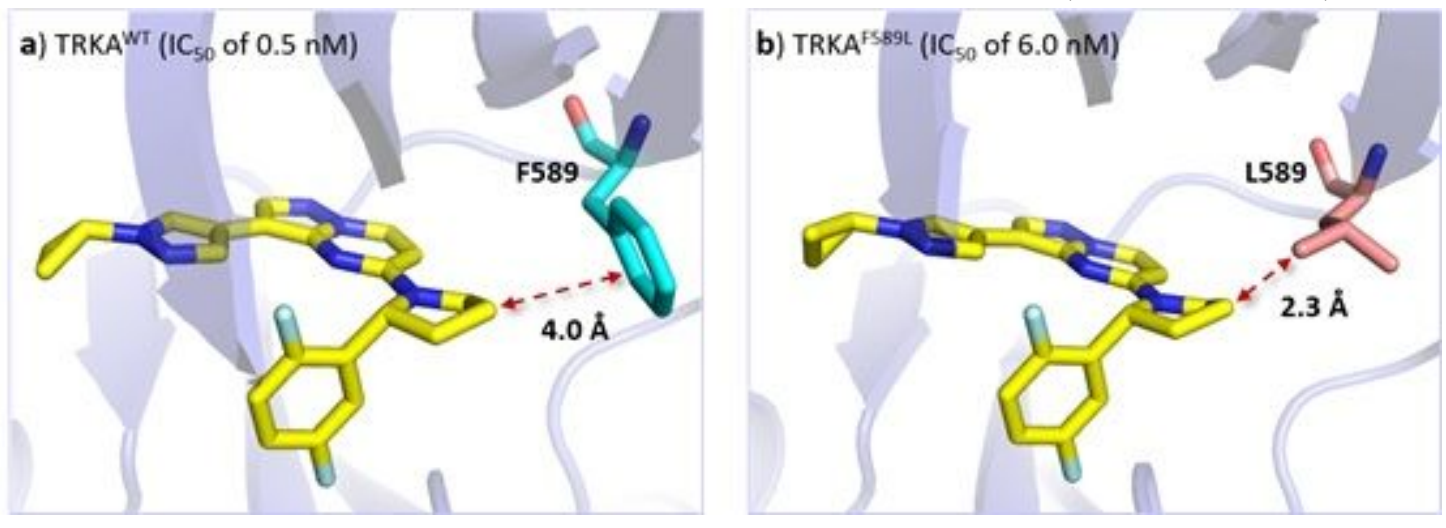

\section{Figure 3}

(A) Proposed binding model of 5m (yellow stick) bound to TRKAWT; (B) Proposed binding and steric interaction of 5m with the TRKAF589L mutant. Residues F589 and L589 are marked in cyan and salmon, respectively. 

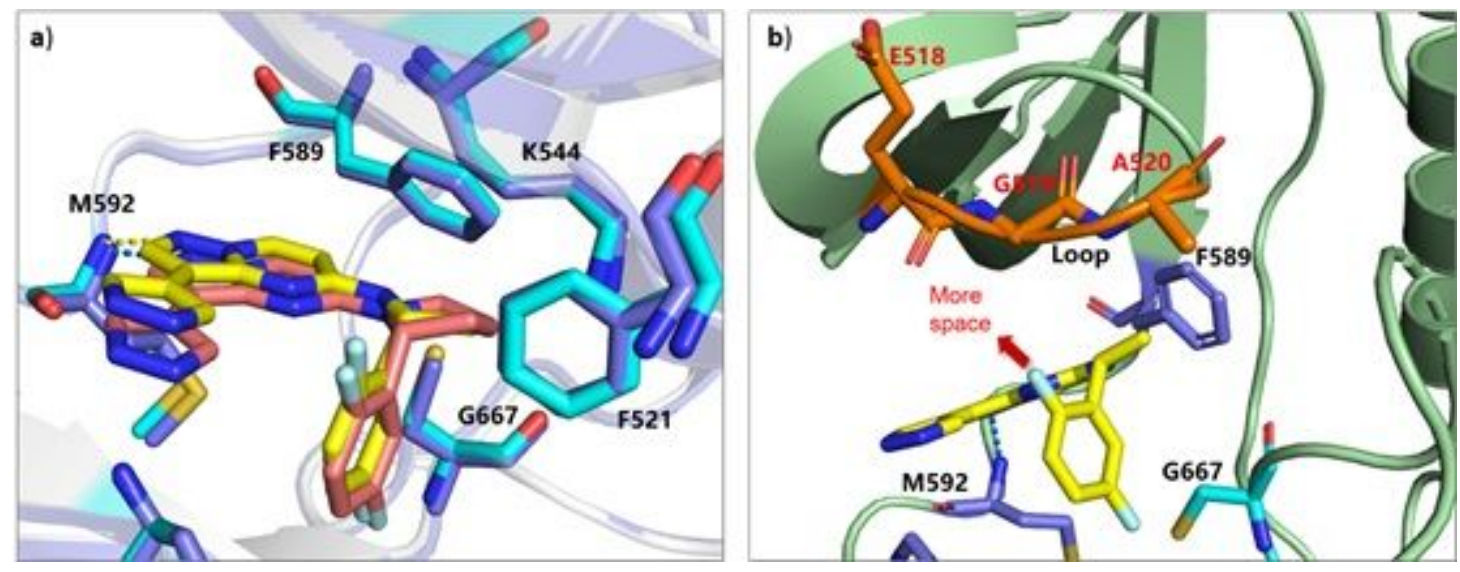

Figure 4

(a) Superposition of proposed binding models of $5 \mathrm{~d}$ (salmon) and 6b (yellow) with TRKAG667C; (b) A view of proposed binding model of $6 \mathrm{~b}$ (yellow stick) bound to TRKAG667C.
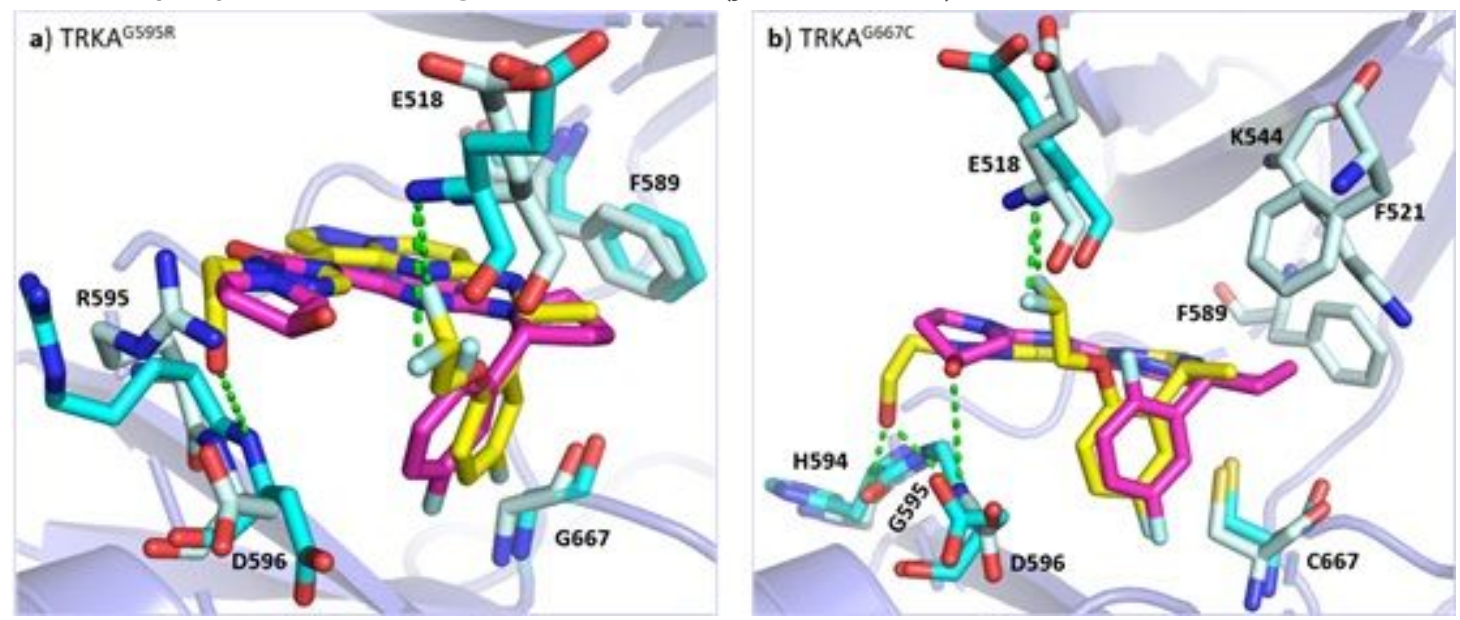

Figure 5

(a) Superposition of proposed binding models of $7 \mathrm{~g}$ (yellow) and 1 (magenta) with TRKAG595R; (b) Superposition of proposed binding models of $7 \mathrm{~g}$ (yellow) and 1 (magenta) with TRKAG667C. Residues are marked in cyan for $7 \mathrm{~g}$ and pale cyan for 1 . Hydrogen bonds are indicated by dashed lines.
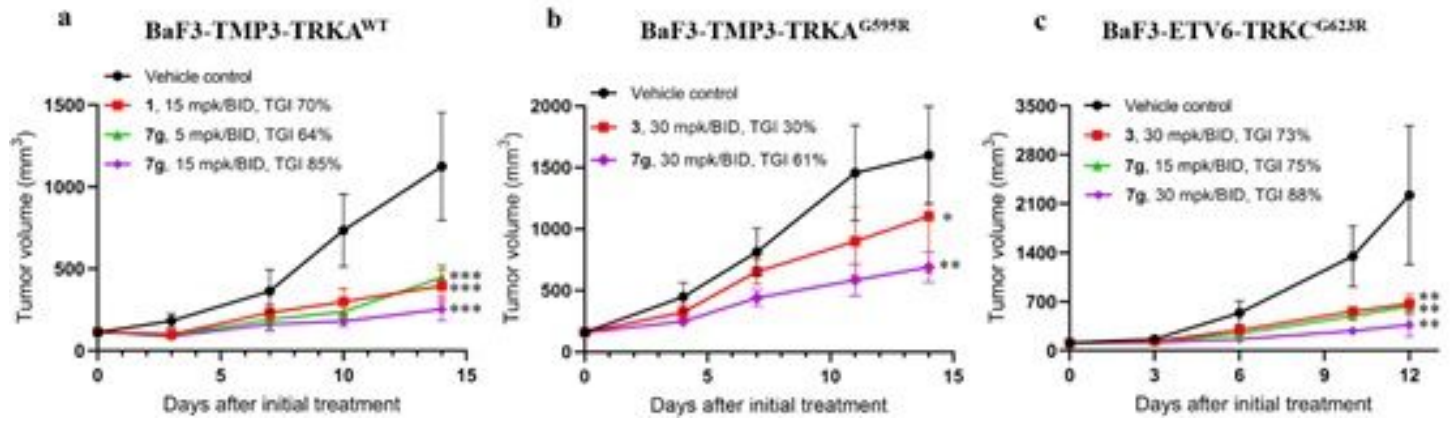

Figure 6 
Antitumor efficacies of $7 \mathrm{~g}$ in the Ba/F3-TMP3-TRKAWT fusion (a), Ba/F3-TMP3-TRKAG595R fusion (b), and Ba/F3-ETV6-TRKCG623R fusion (c) xenograft model. Data are presented as the mean ( \pm SEM; $n=6$ mice per group); BID, bis in die; TGI, tumor growth inhibition; Significant differences from the vehicle group were determined using Student's t test, ${ }^{*} P<0.05, * \star P<0.01$, ${ }^{\star \star \star} P<0.001$.

\section{Supplementary Files}

This is a list of supplementary files associated with this preprint. Click to download.

- Schemes.pdf

- SupplementaryInformation20210606.docx

- NCOMMS2121849reportingsummary.pdf 